\title{
A formação de enfermeiros nos cenários da prática assistencial em saúde da mulher: uma experiência de articulação entre a academia e o serviço
}

Nurses' training in woman's health care practice: A theory and practice cooperation experience

\section{Introdução: apresentando as ações extensionistas}

A educação dos profissionais de saúde deve ser entendida como um processo permanente na vida profissional, por meio do estabelecimento de relações de parceria entre as instituições de educação, de saúde, a comunidade, as entidades e outros setores da sociedade civil ${ }^{1}$. Portanto, aponta-se a necessidade de ações coletivas com a articulação entre estes espaços e agentes no campo da saúde, possibilitando a concretização dos princípios e diretrizes do Sistema Único de Saúde (SUS).

Como unidade acadêmica formadora, a Faculdade de Enfermagem da Universidade do Estado do Rio de Janeiro (ENF/UERJ) tem a formação de enfermeiros pautada na educação crítica, representando o caminho escolhido por essa instituição universitária desde a reforma curricular ocorrida nos anos 90.

Nos dois últimos períodos do curso de graduação em enfermagem, $8^{\circ}$ e $9^{\circ}$ períodos, seus discentes vivenciam mais intensamente a prática do cuidado de enfermagem nos serviços, cenários de estágio supervisionado, sendo essa fase da formação denominada internato.

Em relação ao segmento pertinente à saúde da mulher, os principais objetivos a serem alcançados são: assistir a mulher durante as fases do ciclo vital, considerando-a como sujeito principal destes processos e respeitando seus direitos de cidadania; desenvolver atividades educativas relacionadas à promoção e prevenção em saúde e realizar cuidado ginecológico, à gestação, ao parto e puerpério, assim como ao neonato.
Adriana Lenho de Figueiredo Pereira', Patrícia Lima Pereira Peres $^{2}$, Liana Viana Ribeiro ${ }^{3}$, Erivan Silva de Lyra ${ }^{4}$

\section{Resumo}

O relato aborda as atividades de extensão do projeto Práticas educativas e formação profissional em enfermagem: articulação ensino-serviço. O objetivo é descrever as experiências de extensão voltadas para a articulação entre a academia e o serviço durante a formação de enfermagem nos cenários de atenção à saúde da mulher. A metodologia constituiu um trabalho cooperativo e participativo para a integração docente e discente nas práticas assistenciais e educativas dos serviços e a colaboração dos enfermeiros preceptores na formação discente. Observou-se que as atividades de extensão favoreceram a relação docente-assistencial, a integração entre a unidade acadêmica e o serviço e a implementação de práticas de educação em saúde durante a formação. Concluiu-se que as atividades de extensão promovem o trabalho colaborativo entre a universidade e os serviços de saúde que qualificam a formação de enfermeiros.

Palavras-chaves: Saúde da mulher; Serviços de saúde; Educação em enfermagem; Cuidados de enfermagem

Área Temática: Educação Linha da Extensão: Educação profissional; Atenção integral à mulher

\footnotetext{
Professora Adjunta do Departamento de Enfermagem Materno-Infantil. Faculdade de Enfermagem da Universidade do Estado do Rio de Janeiro E-mail: adrianalenho.uerj@gmail.com.

2 Professora Assistente do Departamento de Enfermagem Materno-Infantil. Faculdade de Enfermagem da Universidade do Estado do Rio de Janeiro E-mail: patricia.uerj@hotmail.com.

${ }^{3}$ Bolsista de Extensão. Acadêmica de Enfermagem.

Faculdade de Enfermagem da Universidade do Estado do Rio de Janeiro. E-mail: liana vian@hotmail.com.

E-mail: liana_vian@hotmail.com.

${ }^{4}$ Enfermeiro do Departamento de Treinamento e Ensino em Saúde. Secretaria Municipal de Saúde e Defesa Civil do Rio de Janeiro E-mail:erivanlyra@uol.com.br.
} 
Esses objetivos permeiam também as metas na formação de enfermeiros especialistas durante o curso de especialização em enfermagem obstétrica na modalidade de residência. Este curso foi resultante de um convênio formal entre a ENF/ UERJ, representada pelo Departamento de Enfermagem Materno-Infantil (DEMI), e a Secretaria Municipal de Saúde (SMS/RJ), tendo seu início em 2004.

Embora com nível de complexidade diferente, há cenários de prática comuns na formação dos internos e residentes no campo da saúde da mulher, representados por um Centro de Saúde, um Centro de Parto Normal e cinco Maternidades da rede municipal de saúde. Assim, as ações articuladas entre a unidade acadêmica e esses serviços possuem significativa importância na formação de enfermagem, motivando a proposta do projeto de extensão "Práticas Educativas e Formação Profissional em Enfermagem: articulação ensino-serviço", tendo iniciado suas atividades em março de 2009.

Esse projeto tem como principal objetivo estabelecer estratégias de intercâmbio de conhecimentos e experiências de educação e assistência de enfermagem nos cenários de atenção do SUS, sobretudo aqueles voltados para a saúde da mulher e perinatal.

As ações extensionistas propostas partem de duas perspectivas fundamentais. A primeira refere-se às estratégias de articulação e integração entre a academia e as instituições de saúde para a formação de profissionais capazes de desenvolver mudanças potenciais no modelo hegemônico de cuidado à saúde, como proposto nas políticas de saúde e de educação para o SUS.

A segunda perspectiva norteadora baseia-se na compreensão de que a formação de enfermeiros é contínua, permanente e envolve o movimento de prática-teoria-prática, e que as instituições de saúde são espaços privilegiados de aprendizagem, em que estão imersos os discentes, docentes, preceptores e usuários que compartilham experiências de cuidado.

Discorrido sobre essas premissas, o presente relato objetiva descrever as experiências de extensão voltadas para a articulação entre a academia e o serviço durante a formação de enfermagem nos cenários de atenção à saúde da mulher.

\section{A opção teórico-filosófica na formação em enfermagem}

O movimento da reforma sanitária concretizou o SUS como um sistema baseado no princípio da cidadania, que assegura a participação da população, a universalidade do acesso, a equidade e a integralidade da atenção. No campo da educação, os pensadores das correntes da educação crítica defendem transformações na prática pedagógica, tendo em vista superar as desigualdades sociais ${ }^{2}$. Decidimos, portanto, focalizar nossa atenção para a pedagogia libertadora ou da problematização por possibilitar uma formação de enfermeiros capazes de compreender os determinantes históricos, políticos e culturais das questões de gênero, dos modelos de atenção à saúde da mulher e do processo de trabalho em saúde.

Na pedagogia da problematização, a educação é uma atividade em que professores e alunos são mediatizados pela realidade que apreendem e da qual extraem o conteúdo da aprendizagem e atingem um nível de consciência dessa realidade, a fim de nela atuarem, possibilitando a transformação social.

Nessa pedagogia, o método de ensino se baseia na relação dialógica entre os atores da aprendizagem, tanto alunos quanto professores. Para Freire ${ }^{3}$, o diálogo viabiliza a verdadeira comunicação, na qual os interlocutores são ativos e iguais. A comunicação é uma relação social igualitária, dialogal, que produz conhecimento. A dialogicidade é fundamental para o pensamento crítico e a educação libertadora.

Pautadas nessa vertente pedagógica, as ações extensionistas visam desenvolver as potencialidades da formação de enfermeiros que respeitem os direitos e a autonomia das mulheres, promovendo o acesso à informação, a liberdade de escolha, a assistência à saúde sem violência e discriminação e o alinhamento com os princípios e diretrizes da Política Nacional de Atenção Integral à Saúde da Mulher.

Essa política preconiza que a humanização e a qualificação da atenção em saúde envolvem o compartilhamento de saberes e o reconhecimento de direitos. As ações procuram articular vários campos de conhecimento necessários ao cuidado integral à mulher e ser um instrumento de garantia dos direitos das mulheres nas ações de saúde ${ }^{4}$. 
Nesse sentido, o cuidar em enfermagem deve necessariamente resgatar a subjetividade, assegurar direitos inalienáveis e construir relações humanas democráticas, superando as assimetrias de poder que ainda permeiam nossa sociedade, em particular na assistência à saúde da mulher.

\section{Metodologia: o método do trabalho de extensão}

O projeto de extensão conta com a colaboração de uma bolsista e envolve cerca de quarenta internos do último período de graduação e vinte residentes de enfermagem obstétrica. Os docentes da ENF/UERJ acompanham diretamente o estágio supervisionado dos internos; as residentes têm sua prática assistencial acompanhada pela preceptoria e pelos supervisores.

Os usuários dos serviços são prioritariamente mulheres que vivenciam o processo gravídico-puerperal e a maternidade. No entanto, estão incluídos seus filhos recém-nascidos e seus familiares que as acompanham nos cuidados e nas atividades educativas no pré-natal, no parto e no pós-parto.

As ações de extensão são desenvolvidas por meio de um trabalho cooperativo e participativo para a integração do docente e do discente nas atividades assistenciais e educativas nos serviços e dos enfermeiros preceptores ao ensino e aprendizagem dos discentes nos cenários de práticas.

\section{Resultados: principais estratégias desenvolvidas}

Iniciamos o trabalho buscando aprimorar a articulação entre o ensino e o serviço por meio do compartilhamento nas atividades de planejamento, desenvolvimento e avaliação das atividades pedagógicas no serviço.

Encontros foram realizados, sendo identificadas necessidades de estabelecer estratégias para um trabalho participativo e colaborativo entre a academia e o serviço, visando à qualificação do cuidado aos seus usuários. Para tal, foi sugerida a participação mais ativa dos docentes e discentes no serviço e da preceptoria no ensino.

Para a preceptoria ter maior envolvimento no processo formativo, foi realizada a apresentação do funcionamento administrativo-pedagógi- co da unidade acadêmica e elaborada uma Oficina de Reflexão Pedagógica para Preceptores. Esta iniciativa trabalhou a compreensão de que há um princípio educativo no trabalho, possibilitando ao homem criar, reproduzir e transformar significados e sentidos sobre o mundo 5 . Portanto, a relação entre trabalho, educação, cultura e saúde é determinante no modo de produção de cuidados e nos modelos assistenciais decorrentes.

Essa oficina foi desenvolvida a partir das experiências cotidianas do grupo, discutindo o processo de ensino-aprendizagem, o planejamento e organização das ações, os sentidos da prática educativa, as tendências pedagógicas e suas implicações sobre o modelo de assistência e as atividades educativas no serviço.

Tal iniciativa teve como desdobramento o favorecimento da relação docente-assistencial, com melhor integração à dinâmica do atendimento, sobretudo nas atividades de grupo de gestantes e de acolhimento dos usuários.

As atividades de grupo são realizadas de modo participativo, estimulando o debate acerca dos temas propostos e voltadas para a compreensão dos direitos reprodutivos e da gestação, parto e nascimento como fenômenos fisiológicos da vida humana.

Foram confeccionados materiais informativos de apoio sobre os direitos da mulher e do pai, inclusive os trabalhistas, a Lei Federal do Acompanhante no Parto (Lei ${ }^{\circ}$. 11.108/2005), o planejamento familiar e para o incentivo do parto normal e da amamentação.

A incorporação dos discentes nessas atividades possibilitou a vivência dos pressupostos da educação em saúde e em enfermagem, abordados nas disciplinas da graduação e da especialização, o que modificou a centralidade da formação em procedimentos técnicos e incorporou experiências de promoção e de cuidado à saúde voltadas para a construção de valores democráticos no âmbito da assistência obstétrica.

Essa experiência de formação fundamenta-se na co-participação de todos os atores no contexto da educação, da saúde e do trabalho em saúde, manifestando o trabalho como princípio de cidadania e de educação que possibilita mudanças no modelo hegemônico de assistência ao parto, geralmente representado como um evento 
de risco para a mãe e bebê, pouco apoiado em evidências, marcado por uma relação profissional-usuária autoritária, gerando medo e insegurança entre as mulheres no momento do nascimento de seus filhos ${ }^{6}$.

Essas iniciativas motivaram a realização do primeiro Seminário "Experiências de Formação, Assistência e Inovação em Enfermagem Obstétrica do Sistema Único de Saúde", realizado no Teatro Noel Rosa, campus UERJ. Este evento teve a participação de enfermeiros da saúde da mulher e perinatal das Secretarias Estadual e Municipal de Saúde do Rio de Janeiro e proporcionou um espaço de reflexão, discussão e intercâmbio de conhecimentos e experiências acerca da formação e da assistência de enfermagem obstétrica nos cenários de atenção à saúde da mulher no SUS, contribuindo para o debate em relação à temática e aos desafios contemporâneos na educação e assistência de enfermagem.

\section{Conclusão}

As atividades de extensão possibilitam o compromisso social da universidade por meio de ações articuladas de ensino, assistência e difusão do conhecimento científico durante a formação de enfermeiros. O projeto tem uma proposta que supera as tradicionais ações de extensão de cunho assistencialista no campo da saúde, sendo sua relevância educativa, cultural e social situada no âmbito da educação, da assistência e do trabalho de enfermagem.

A presente atividade de extensão é fruto de um trabalho coletivo e de cunho social, com potencialidade de concretizar as recomendações das políticas públicas em saúde. Portanto, desafiador e, ao mesmo tempo, estimulante no sentido da construção de laços indissociáveis entre a academia e o serviço para a formação de enfermeiros qualificados para o exercício do cuidado humano e técnico que atenda às necessidades e anseios das mulheres no campo da saúde.

\section{Referências}

1. BRASIL, Ministério da Saúde; Ministério da Educação. Programa Nacional de Reorientação da Formação Profissional em Saúde Pró-Saúde: objetivos, implementação e desenvolvimento potencial. Brasília: Ministério da Saúde, 2007.
2. PEREIRA, Adriana Lenho de F. As tendências pedagógicas e a prática educativa nas ciências da saúde. Cad. Saúde Pública, Rio de Janeiro, v.19, n. 5, p.1527-34, set/out, 2003.

3. FREIRE, Paulo. Pedagogia do Oprimido. 44. ed. Rio de Janeiro: Editora Paz e Terra. 2005. 213 p.

4. BRASIL, Ministério da Saúde. Política Nacional de Atenção Integral a Saúde da Mulher. Brasília (DF): Ministério da Saúde. 2004. 82 p.

5. FRIGOTTO, Gaudêncio. Educação e trabalho: bases para debater a educação profissional emancipadora. Perspectiva, Florianópolis, v. 19, n.1, p.71-87, jan./ jun. 2001.

6. DINIZ, Simone G. Gênero. Saúde materna e o paradoxo perinatal. Rev Bras Crescimento Desenvolv Humano, São Paulo, v.19, n. 2, p. 313-26, ago. 2009.

\section{Abstract}

The article addresses the extension activities of project Education practices and professional training in nursing: Theory and practice cooperation the objective of describing the extension experiences of cooperation between theory and practice during the nursing training in women health care context. Methodology comprised co-operative and participative work for the integration of professors and students in welfare and educational practices of services and the support of instructor nurses to the students' education. Extension activities fostered the professor-care ratio, the integration between the academic unit and service and implementation of health education practices during the training. We concluded that extension activities promote collaborative work between university and health care services qualifying nurses' education in health care services.

Keywords: Women's health; Health care services; Nursing education; Nursing care 